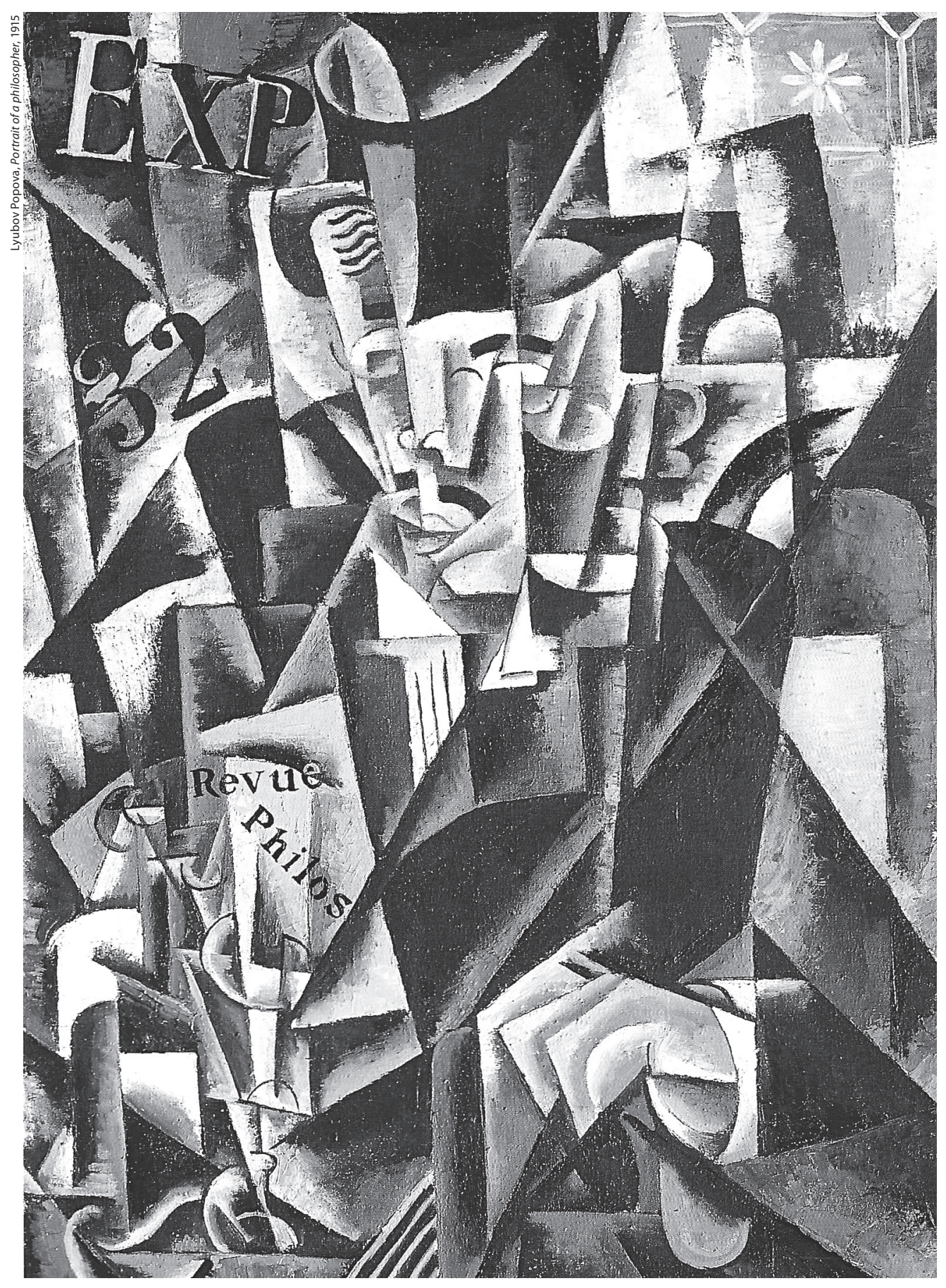

\title{
Encontros com V. V. Ivánov
}

Jerusa Pires Ferreira 


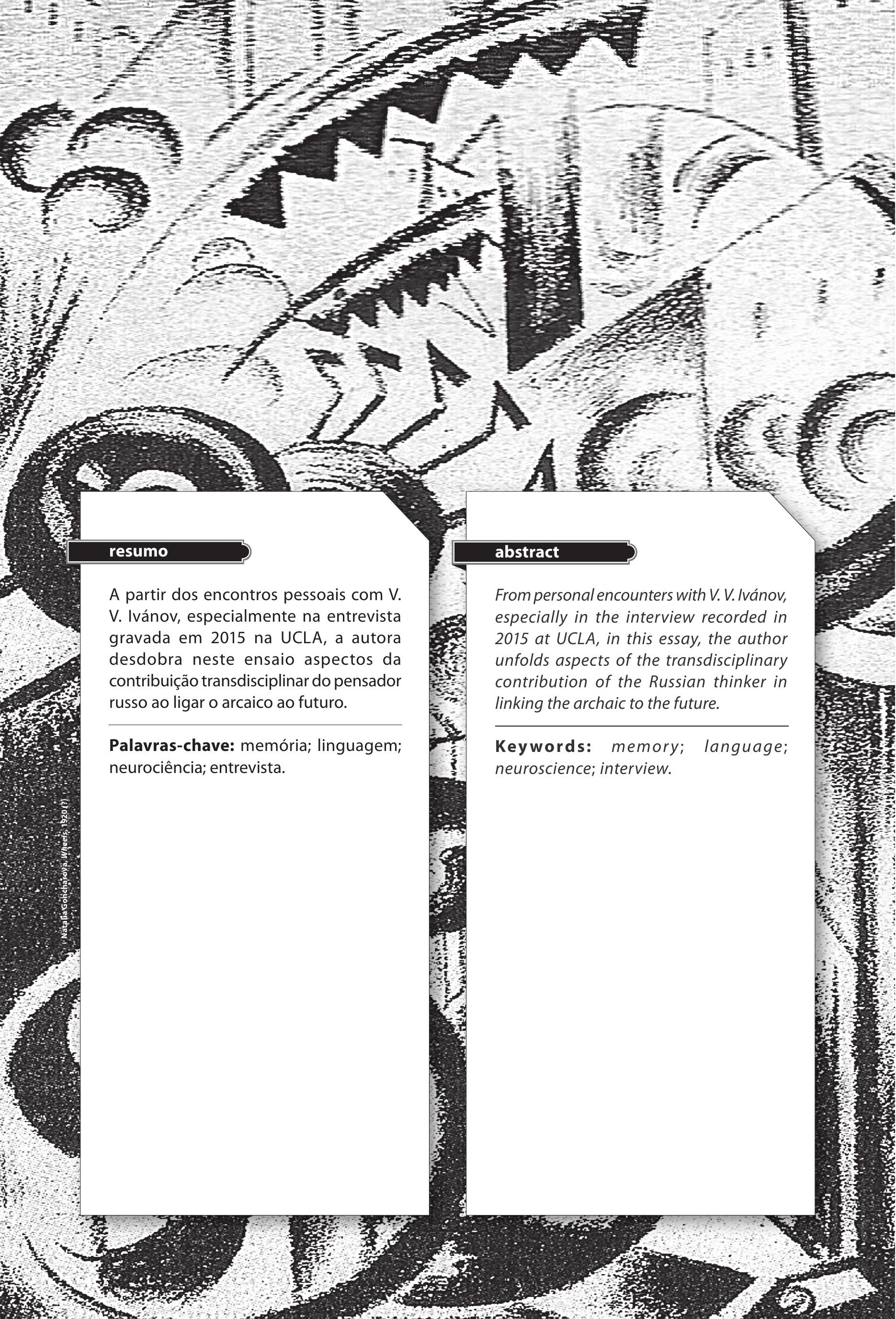




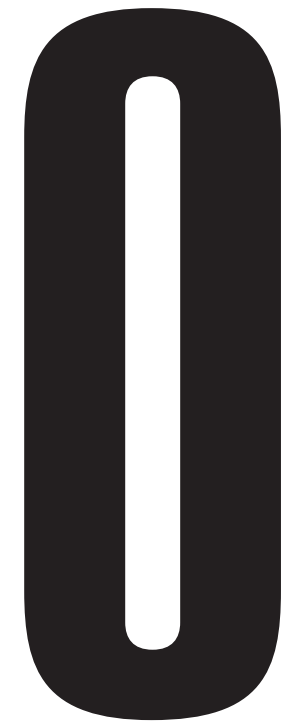

$\mathrm{s}$ encontros com o grande semioticista e pensador russo desenvolveram-se há cerca de 40 anos. Começam com a aproximação, a partir da iniciativa tomada nos anos 1960 por Boris Schnaiderman, que o visitou e, além de manter correspondência com ele, ainda nos tempos soviéticos, publicou na imprensa artigos e, em coletâneas, alguns trabalhos de Ivánov (Moscou, 1929-Los Angeles, 2017).

Ao lidar com o pensador percebemos como ele constitui uma parte da história contemporânea, e faz aflorar uma específica relação Brasil-Rússia.

Em 1987, estivemos em Moscou, durante as transformações no âmbito do que se chamou Perestroika. Pudemos seguir de longe sua atuação como deputado no Soviete Supremo. E, a partir daí, passamos a ter encontros regulares, ao longo de 30 anos, com aquele que seria um dos maiores semioticistas e pensado- res da cultura, sempre comprometido com ciências, poética, educação e política. Em 1990, ele veio ao Brasil convidado pelo curso de Russo da USP e, em especial, por Aurora Bernardini. Daí resultou um intenso e profícuo convívio. Em 1994, o encontramos no congresso Semiotics Around the World, na Universidade de Berkeley, Califórnia, quando houve ocasião de seguirmos, bem de perto, princípios e formulações de seu pensamento.

No ano de 1997, estivemos novamente em Moscou e, em 2008, passamos um período trabalhando juntos, discutindo princípios e ideias em sua casa de Pierediélkino, lugar lendário, antiga residência de escritores e pensadores como Boris Pasternak e Mikhail Bakhtin.

Professora e pesquisadora do Programa de Pós-Graduação em Comunicação e Semi-

JERUSA PIRES FERREIRA foi professora do Programa de Pós-Graduação em Comunicação e Semiótica (COS) da PUC-SP, onde dirigiu o Centro de Estudos da Oralidade, e da ECA-USP. É autora de, entre outros, Cavalaria em cordel (Edusp) e Fausto no horizonte (Educ). 
ótica (COS) da PUC-SP, e aí lecionando a disciplina Semiótica da Cultura, fui preparando com os alunos, ao longo de alguns anos, importantes materiais desse pensador, visando à organização de um volume.

V. V. Ivánov representa grande parte de um século de transformações culturais, sociais, políticas. Pode-se falar em razões do mundo e até na busca de outros universos.

Ele traz uma dimensão extraordinária que liga o arcaico ao futuro. Ao acompanhar sua trajetória, textos, narrativas, sentimos o seu papel de mediador, de um intérprete das ciências e das artes que não só as aproxima, como faz uma ponte entre elas. Por isso, desenvolvo o projeto que se chama "Uma Jornada pelo Conhecimento".

Sua notável incursão na neurociência, parceria de ciências e artes, nos traz uma inovadora questão sobre conhecimento e tecnologias de ponta. Preocupa-se fundamentalmente com educação, em arrojadas concepções, visando sobretudo a uma interferência na educação básica, em operações renovadoras.

Fomos observando como se deu um diálogo permanente que Ivánov manteve ao longo de sua experiência, o interesse por todos os temas e a busca de parcerias, notáveis e singulares.

Aproveitei então para fazer com ele uma entrevista, que transcrevi, e serviu de ponto de partida para o roteiro do mencionado projeto em curso.

Tudo isso está muito bem documentado em arquivos, incluindo fotos de diversas fases e, na sequência, um filme realizado na UCLA, onde estivemos a seu convite. Oferecemos em nossa universidade e visando à comunidade científica resultados concretos de um curso oferecido em dois semestres.
O primeiro, de 2015, teve ótimos resultados e prevê a organização do mencionado livro e a finalização do documentário feito por nós.

\section{VIAGEM AO CONHECIMENTO}

Estive em Los Angeles de 19 de fevereiro a 4 de março de 2015, acompanhando as atividades do mestre e pensador na UCLA. Com a colaboração de Ricardo Pires Ferreira Filho, realizamos uma entrevista filmada, em muitos dias consecutivos. Recolhemos um material mais precioso e extenso do que poderíamos imaginar. São imagens fundamentais referentes ao século XX, à passagem ao XXI, à vigência de nossos tempos e suas projeções. Temos aí o levantamento de muitas pistas para situar memória, história, saúde, pensamento semiótico, educação e novas tecnologias, incluindo a experiência com bibliotecas.

Assim, o curso começou em março de 2015, disponibilizando trechos da entrevista/ encontro, e reunindo alunos, pesquisadores e colegas envolvidos com o tema.

A partir dos materiais trazidos e de suas referências, contamos com a participação dos professores Boris Schnaiderman, Norval Baitello Jr., Aurora F. Bernardini, Amálio Pinheiro, Beth Brait, Anastassia Bytsenko, do poeta Augusto de Campos e de Pedro Niemayer Cesarino. Foram então gravadas as palestras e os depoimentos mencionados, lembrando que é preciso esclarecer que V. V Ivánov e sua esposa Svetlana Ivánova passavam um semestre por ano em Los Angeles (UCLA) e outro semestre em Moscou.

Quanto ao desenvolvimento do curso no COS/PUC-SP, em seu segundo semestre, apresentamos em versão preliminar (20 de agosto 


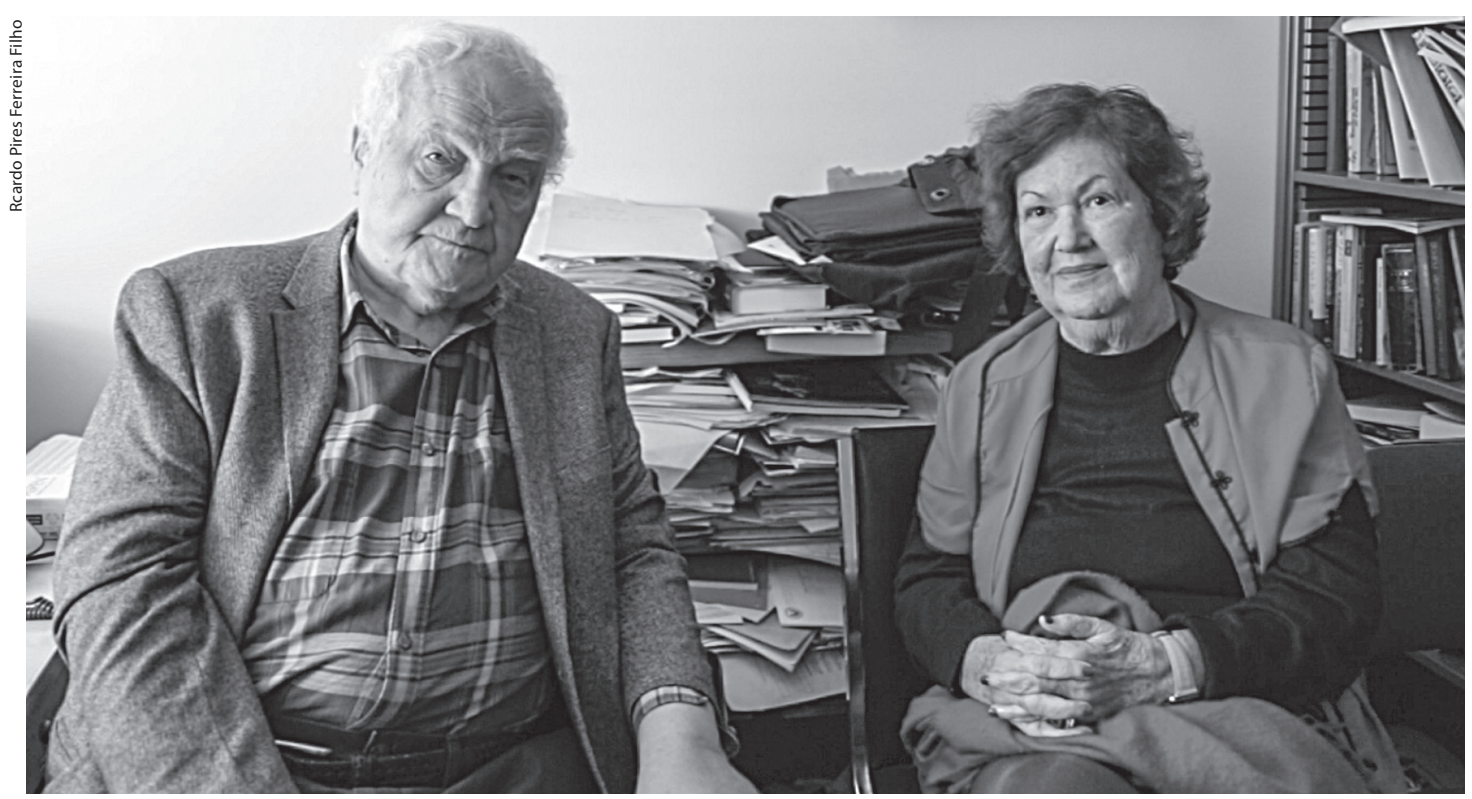

V. V. Ivánov e Jerusa Pires Ferreira, Los Angeles, 2015

de 2015) o filme A journey through wisdom, an interview, com duração de $1 \mathrm{~h} 30$. Além do que foi editado, possuímos muitas horas de gravação do material bruto a ser explorado.

Os tópicos constantes dessa entrevista foram destacados e propostos aos estudantes para discussão e eventual colaboração.

Memória, cognição, neurociências, decifração, linguística, poética, história, arqueologia, vanguardas, criação.

Conseguimos retirar do texto autobiográfico de Ivánov, que traduzimos, Autorretrato de um semioticista russo em seus anos de juventude e de maturidade (1990) referências à leitura, aos livros e biblioteca, e assim atividades foram discutidas e textos publicados ${ }^{1}$.

1 Em meu "Um destino singular: livros, leituras, bibliotecas", mas também em "O tema fáustico em páginas de Ivánov", "Notas sobre Eisenstein", que foi discutido em mesa-redonda na PUC-SP, 17/09/2015; e ainda O grande russo e o pequeno azteca, texto criativo e audiovisual, todos os três inéditos.
Cabe reproduzir a conversa/entrevista que vai nos esclarecendo percursos e oferecendo novas entradas em seu grandioso repertório.

\section{CONVERSA COM IVÁNOV}

Em 30 de junho de 2008, pude conversar com V. V. Ivánov em sua casa de Pierediélkino. Lugar mágico para nós, por tantas referências, residência dos escritores, ameaçado agora pela especulação imobiliária. Foi um intenso momento, em que se desenvolveram para além de um conjunto de temas e fabulações, que passo a contar.

Perguntei, de saída, ao amigo e grande semioticista se ele continuava a dizer-se assim, pois muitos passavam pela semiótica e tomavam depois novos caminhos. Confirmou.

Falou-me de seus projetos e trabalhos, de estar preocupado com a história da escrita e espécies definidas de signos. Não descartou a poesia. Óssip Mandelstam e Boris Pasternak, os poetas escolhidos e próximos. 


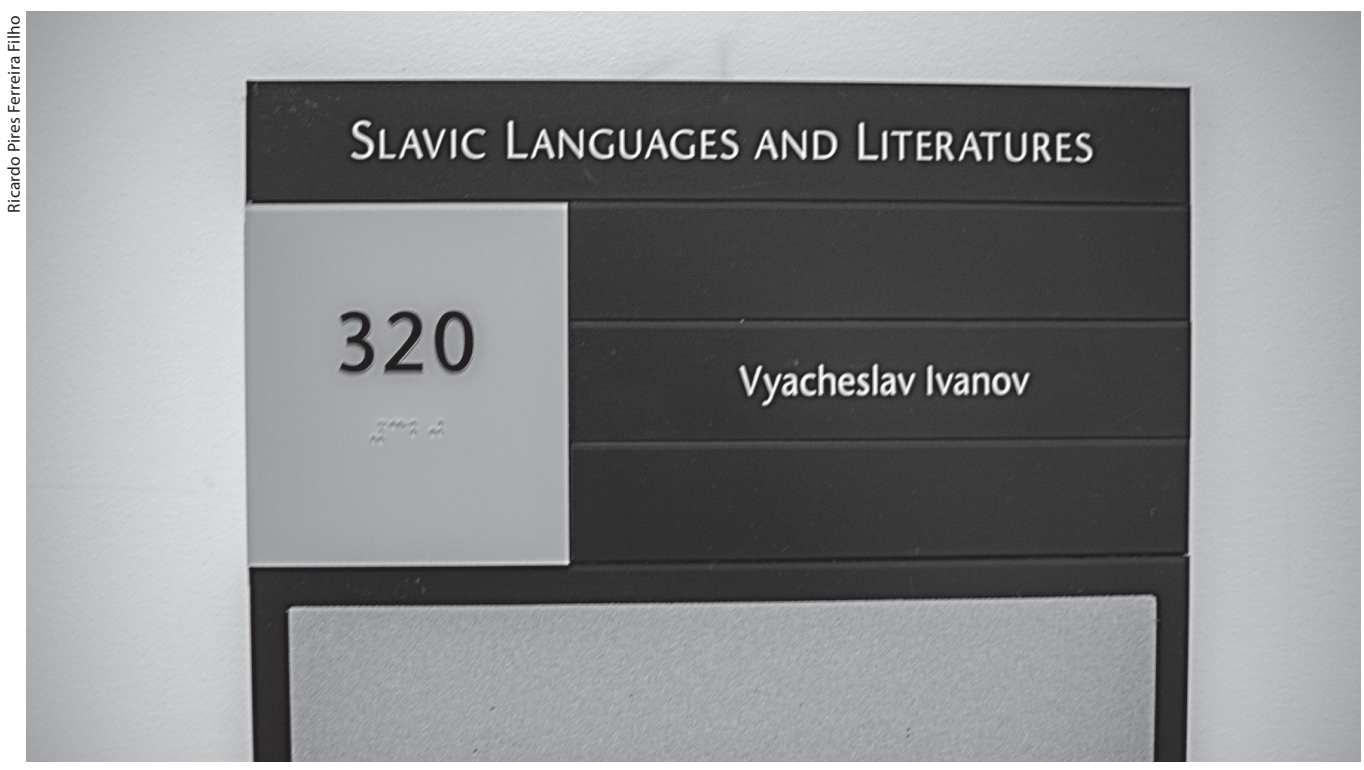

Placa da sala de Ivánov na UCLA

Daí anuncia seu empenho na construção de uma história geral dos signos, destacando então seu grande interesse pela matemática.

Tudo isso fazendo parte do estabelecimento de uma grande comparação entre culturas ocidentais e orientais, o que, ao longo de sua vida, acharia um espaço tão definido.

Reitera o seu interesse por Pável Florênski, conta de um projeto que chama Symbolarium, que, como nos diz, deveria começar por símbolos matemáticos.

Demonstra ainda seu grande interesse pelos estudos cognitivos que compreendem mente, memória, ideia e linguagem e nos leva à nova antropologia cultural, combinando diferentes linguagens, evidenciando o valor da antropologia visual.

Passa a citar nomes para mim desconhecidos como Aronson ${ }^{2}$ e a publicação, em edição particular, do Journal of blue sofa.

2 Elliot Aronson (1932-), psicólogo norte-americano, autor de estudos experimentais sobre a teoria cognitiva e do livro The social animal.
Mas na condição de um dos seus fundamentos, destaca mesmo a obra de Gustav Shpet $^{3}$, Hermeneutics, de 1918, que na ocasião se republicava. E na sequência de suas escolhas, lembra-nos que Santo Agostinho foi o primeiro a distinguir entre ciências das coisas/objetos e ciências dos signos.

Quanto a Roman Luriá ${ }^{4}$, de quem já nos havia falado muitas vezes, importa considerar sua reflexão acerca do cérebro humano e o trabalho com os signos ou os signos no cérebro. Ivánov discorre então sobre o hemisfério esquerdo, sugerindo, em divagação, como seria interessante considerar o funcionamento do cérebro de Eisenstein.

3 Gustav Shpet (1879-1937), psicólogo e teórico russo. Sua contribuição é uma abordagem fenomenológica nos campos da filosofia da linguagem e em teoria da arte.

4 A. R. Luriá (1902-1977), médico russo nascido em Kazan, pioneiro nos estudos sobre memória e funções da linguagem. Cf. tradução brasileira de seu Fundamentos da neuropsicologia. 
No caso de Kandínski, ele nos conta, ocupava-se em pensar uma lista dos elementos que conduziram os passos de sua arte abstrata. As cogitações sobre Kandínski levam a Florênski e à consideração de novos sistemas de símbolos.

As formas do psíquico, os arquétipos (Jung), os arquétipos na arte popular, as possibilidades que reúnem os símbolos naturais, árvores, plantas, animais aos do ser humano. Estes são os caminhos que apontam para a organização do seu anunciado Symbolarium.

Passa então a enumerar alguns símbolos, dando exemplos, quando diz: "Minha ideia é contemplar entre os símbolos matemáticos aqueles que são elementares e os que formam sistemas de escrita”. E diante disso relata contemplar três dimensões na cultura: vanguardas artísticas, tecnologias e conjunto religioso.

E aí nos apresenta as formulações de Schmandt-Besserat". "É que a escrita começou com símbolos", ele nos diz. Aproximam-se os pintores de vanguarda, das novas tecnologias e também das religiões xamanísticas de muitos povos da Rússia. Kandínski, segundo suas palavras, condensa tudo isso. Uma notável síntese.

A memória é um dos mais importantes tópicos na sua vida, disse-lhe, evocando a escuta de suas informações sobre memória e luz, que tantas vezes ouvira em nossas andanças peripatéticas, quando disputávamos, em grupo, o privilégio de captar fragmentos que se transformariam em aberturas para novas cogitações.

Os estudos sobre a eletricidade, aqueles sobre a arte, os "ícones" e os estudos óticos da perspectiva visual prevalecem em suas referências, e passa a nos informar que o monge Pável Florênski, fuzilado em 1937, estava a dois passos de inventar o computador.

As notas que então recolhi (abandonando um gravador que não funcionou) deixam bem claro como fica difícil situar um conjunto tão amplo, complexo, do proposto ao vivenciado por esse notável pensador. Com seu modo sincopado de enunciar, ele vai trazendo sempre novas sugestões, oferecendo nomes de cientistas afins, personagens que passam a construir todo um quadro de referências a que nos convida.

Para isso seriam necessários muitos anos de observação e convívio, um verdadeiro desafio para cada um que aí se lance. Trata-se de uma tarefa a ser encarada com humildade, sem abrir mão do arrojo e determinação.

E como nos diz Lucio Agra, participante desses encontros, Ivánov é dessas figuras extraordinárias e singulares que transcendem todas as divisões. Um dos grandes pensadores da linguagem cujo desaparecimento se comunica com o futuro. 


\section{REFERÊNCIAS}

IVÁNOV, Vyacheslav. "Self-portrait of a russian semiotician in his younger and later years", in Thomas Sebeok (ed.). Semiotic web. Berlin/New York, Mouton de Gruyter, 1990. LURIÁ, Alexander Romanovich. Fundamentos da neuropsicologia. Trad. Juarez Aranha Ricardo. Rio de Janeiro/São Paulo, Livros Técnicos e Científicos/Edusp, 1981.

PIRES FERREIRA, Jerusa. "Um destino singular: livros, leituras, bibliotecas". Revista Livro, n. 5. São Paulo, Nele/USP, nov./2015. 